\title{
Preauricular Sinus as Recurrent Postaural Abscess: A Rare Presentation
}

Sharanabasappa Rudragouda Malipatil

\section{ABSTRACT}

Preauricular sinus (PAS) is not uncommon congenital anomaly. It is usually asymptomatic and does not require any treatment. Patient presenting with discharge, recurrent infections and preauricular abscess will require management with antibiotics and surgical extirpation of the sinus tract. Here, it is a rare case report of PAS presenting as a recurrent postaural abscess.

Keywords: Preauricular, Sinus, Postaural, Abscess.

How to cite this article: Malipatil SR. Preauricular Sinus as Recurrent Postaural Abscess: A Rare Presentation. Int J Otorhinolaryngol Clin 2014;6(2):84-86.

\section{Source of support: Nil}

Conflict of interest: None

\section{INTRODUCTION}

Preauricular sinus (PAS) is not uncommon congenital anomaly. It is usually asymptomatic and does not require any treatment. Patient presenting with discharge, recurrent infections and preauricular abscess will require management with antibiotics and surgical extirpation of the sinus tract. Here, it is a rare case report of PAS presenting as a recurrent postaural abscess.

\section{CASE REPORT}

An 8-year-old boy presented with swelling and pain in the left postaural region of 1 week duration. He also gave history of six episodes of abscess in the left postaural region since the past 2 years for which he was treated by incision and drainage with antibiotics. There was no history of hearing loss, discharge from ear or trauma. On ear, nose and throat (ENT) examination, the patient had a PAS just below the ascending limb of the helix. Pinna was swollen and tender. The external auditory canal and tympanic membrane were normal. The postaural region showed a soft, fluctuant and tender swelling with scars and sinus on the surface (Fig. 1).

Associate Professor

Department of ENT and Head and Neck Surgery, Shri BM Patil Medical College, Bijapur, Karnataka, India

Corresponding Author: Sharanabasappa Rudragouda Malipatil Associate Professor, Department of ENT and Head and Neck Surgery, Shri BM Patil Medical College, Bijapur, Karnataka, India Phone: 9341083859, e-mail: sharnu_rmp@yahoo.co.uk
The audiological examination was normal, and the X-ray mastoid Schüller's view showed a normal pneumatized mastoid air cells. He was provisionally diagnosed as a case of recurrent postaural abscess with perichondritis. The patient was treated with culture and sensitivity based antibiotics and analgesics.

After control of perichondritis, the patient was taken up for debridement of the postaural abscess and sinus under general anesthesia. A postaural incision was placed after infiltration with lignocaine and adrenaline. It was seen that, on meticulous removal of the fibrotic tissue and infected sinus tissue, the main sinus tract was visualized extending anteriorly through the conchal cartilage (Fig. 2). Methylene blue stain was injected in the PAS opening which filled and

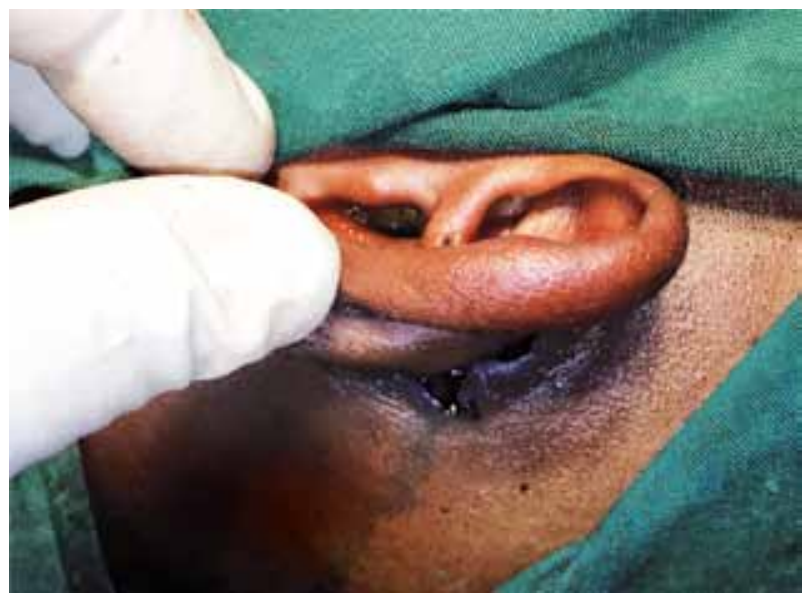

Fig. 1: The postaural region—soft, fluctuant and tender swelling with scars and sinus on the surface

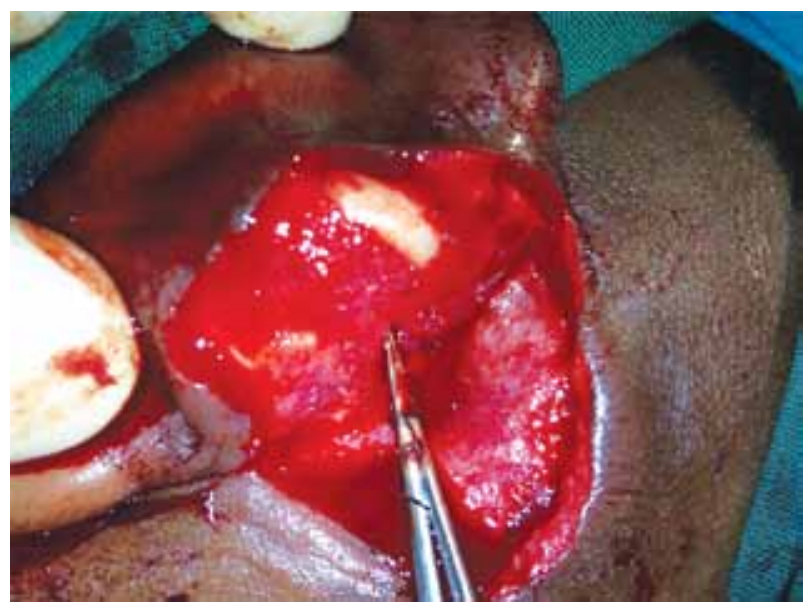

Fig. 2: The main sinus tract extending anteriorly through the conchal cartilage 


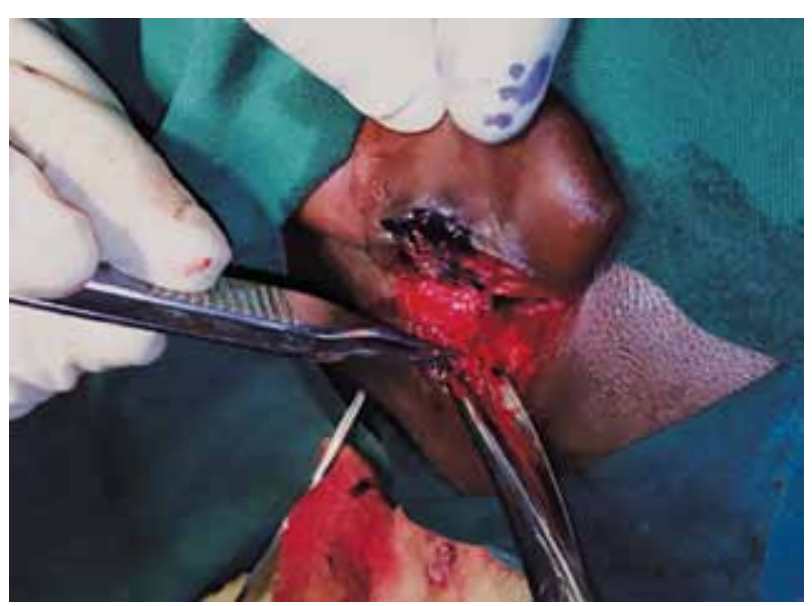

Fig. 3: Methylene blue stain injected in the PAS opening which filled and spilled into the postaural abscess area

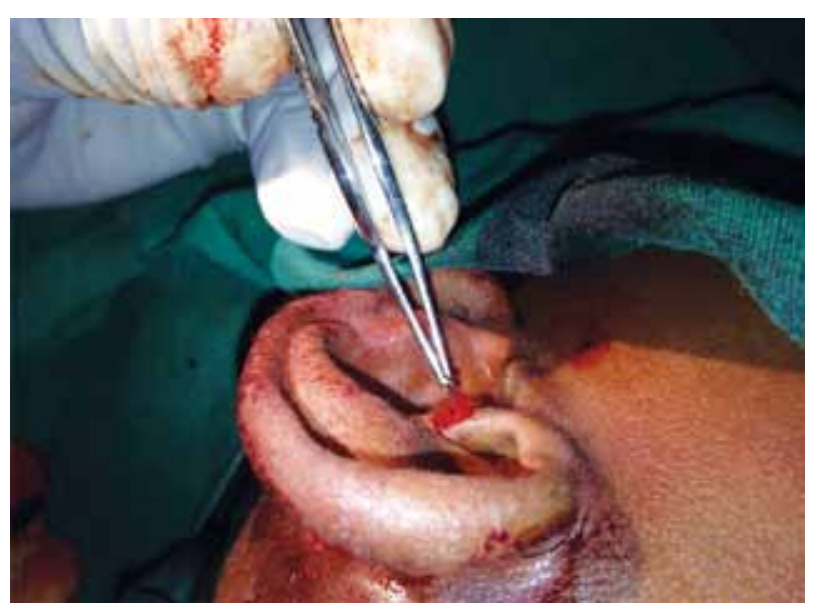

Fig. 4: Removal of sinus pit and tract in toto in combination with a preauricular wedge incision around the PAS pit

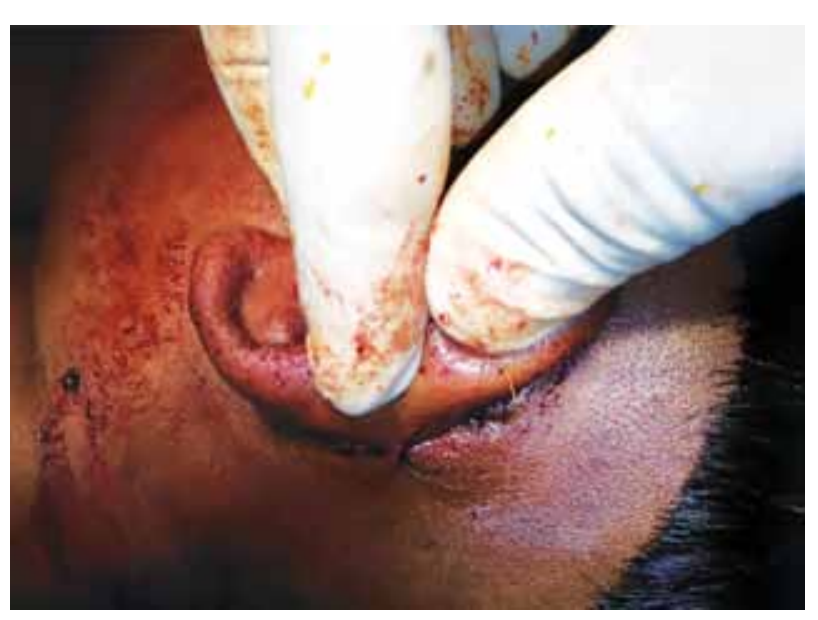

Fig. 5: Wound closure in layers

spilled into the postaural abscess area (Fig. 3). The tract was followed and was seen to be extending into the PAS. The sinus pit and tract was removed in toto in combination with a preauricular wedge incision around the PAS pit (Fig. 4). Wound was closed in layers (Fig. 5), and mastoid bandage given. Postoperative period was uneventful, and the patient has been asymptomatic since last 6 months.

\section{DISCUSSION}

Preauricular sinus is a common congenital anomaly in children which was first described in 1864 by Heusinger. ${ }^{1}$ Various terms like preauricular pit, preauricular fistula, preauricular tract and preauricular cyst are used synonymously with this condition. It has an estimated incidence of 0.1 to $10 \%$ with higher incidence among Asians and Africans. ${ }^{2}$

Preauricular sinus is formed during 6th month of gestation and closely related to the development of the auricle. The most accepted theory of development states that it is formed by the incomplete or defective fusion of the six mesenchymal proliferations called the hillocks of his. The other theory describes it as an isolated ectodermal folding which forms an inclusion dermoid during auricular development.

Fifty percent cases of PAS are unilateral, occur sporadically and are on the right side. ${ }^{3}$ Bilateral cases are usually inherited and the pattern is of autosomal dominance with reduced penetrance and is linked to chromosome 8q11.1 to q13.3. ${ }^{4}$ Preauricular sinus may also be related to branchiogenic fistulas, hearing loss and renal malformations, and a extensive evaluation is necessary to rule out any other malformations.

Due to its embryology, it is closely related to the groove between ascending limb of helix and the tragus and presents as a small opening. The opening can also be along the posterosuperior margin of the helix, the tragus or the lobule. It may be multibranching and ramifying within the preauricular soft tissue and is usually closely related to the perichondrium of the auricle.

In the classical cases of PAS, the pits are located anterior to an imaginary line extended from tragus to the posterior margin of the ascending limb of the helix, and the patients may present with recurrent abscess in the preauricular region. Variant presentations as seen in our case, the pit is located posterior to the imaginary line with the patient presenting with postauricular abscess which may be confused with other pathology. ${ }^{5}$

It is a common anomaly which is usually asymptomatic and is noted during routine ENT examination but it may also present as discharging sinus, recurrent infections with abscess and facial cellulitis. The most common pathogens causing infection are Staphylococcus epidermidis, Staphylococcus aureus, Streptococcus viridans, Peptococcus sp. and Proteus sp. ${ }^{6}$ Postauricular abscess is an uncommon presentation of the PAS with few references in literature. ${ }^{7,8}$ It can be mistaken for other postaural pathology, like postaural 
lymphadenitis, sebaceous cyst, epidermoid cyst, mastoid abscess, perichondritis and branchial cleft cyst. Our patient had reported with recurrent postaural abscess which was treated earlier with incision and drainage and antibiotics elsewhere.

The principles of treatment are complete excision of the pit and sinus sac during the period of quiescence after treating active infection with culture and sensitivity based antibiotics. Various techniques of excision of classical PAS include anterior and supra-auricular approaches, injection of methylene blue for delineation of tract and use of microscope for magnification. In our case, the tract was seen extending through the conchal cartilage and had to be excised by a combined anterior and posterior approach with the help of operating microscope.

The standard technique for excision has a recurrence of 19 to $42 \%$ with the supra-auricular approach reporting a low rate of $5 \% .{ }^{9,10}$ The cause of recurrence is usually due to difficult identification of tract in patients with recurrent infections, with scarring and fibrosis of the preauricular soft tissue leading to inadequate removal of all the ramifications of the tract. ${ }^{11}$ The case is being reported as it is a rare presentation of a common congenital anomaly. The history of recurrent infections and swellings around the ear along with presence of a PAS should alert the otolaryngologist regarding the diagnosis.

\section{REFERENCES}

1. Heusinger CF. Hais-Kiemen-Fisteln von noch nicht beobachteter form. Virchows Arch 1864;29:358.

2. Lam HCK, Soo G, Wormald PJ, Van Hasselt CA. Excision of the preauricular sinus: a comparison of two surgical techniques. Laryngoscope 2001;111:317-319.

3. O'Mara W, Guarisco L. Management of the preauricular sinus. J La State Med Soc 1999;151:447-450.

4. Zou F, Peng Y, Wang X, Sun A, et al. A locus for congenital preauricular fistula maps to chromosome 8q11.1-q13.3. J Hum Genet 2003;48:155-158.

5. Choi SJ, Choung YH, Park K, Bae J, Park HY. The variant type of preauricular sinus: postauricular sinus. Laryngoscope 2007; 117(10):1798-1802.

6. Scheinfeld NS, Silverberg NB, Weinberg JM, Nozad V. The preauricular sinus: a review of its clinical presentation treatment, and associations. Pediatr Dermatol 2004;21:191-196.

7. Chang $\mathrm{PH}, \mathrm{Wu} \mathrm{CM}$. An insidious preauricular sinus presenting as an infected postauricular cyst. Int J Clin Pract 2005;59: 370-372.

8. Yeo SW, Jun BC, Park SN, et al. The preauricular sinus: factors contributing to recurrence after surgery. Am J Otolaryngol 2006;27:396-400.

9. Currie AR, King WW, Vlantis AC. Pitfalls in the management of preauricular sinuses. Br J Surg 1996;83:1722-1724.

10. Prasad S, Grundfast K, Milmoe G. Management of congenital preauricular pit and sinus tract in children. Laryngoscope 1990;100:320-321.

11. Nair S, James E, Chugh R. An unusual case of recurrent postaural abscess. Ind J Otolaryngol Head Neck Surg 2011 Jul;63(Suppl 1): 58-60. 